\title{
Lenz y Manquilef: la creación de un sujeto étnico
}

\author{
Fernando Ruiz Figueroa ${ }^{1}$ \\ Investigador independiente, Chile
}

\begin{abstract}
Resumen
A través del análisis discursivo de los paratextos presentes en los "Comentarios del Pueblo Araucano" de Manuel Manquilef 1911), el presente estudio demuestra cómo se expresa una ideología que relega a la lengua y la cultura mapuche al folclore propiamente chileno. Rodolfo Lenz, como editor de este texto, se presenta como autoridad que dirige la lectura del texto central de Manquilef, presentándola como la materia prima útil para conformar la identidad nacional chilena.
\end{abstract}

Palabras claves: Manquilef, Lenz, paratextos, folclore.

LENZ AND MANQUILEF: THE CREATION OF AN ETHNIC SUBJECT

Abstract

Through the discourse analysis of the paratexts present in Manuel Manquilef's book: "Comentarios del Pueblo Araucano" (1911), this

1 Para correspondencia, dirigirse a: Fernando Ruiz Figueroa (fer.ruiz.f@gmail.com), Barros Arana 452, población Modelo, Puerto Montt. 
study demonstrates how an ideology that relegates Mapuche language and culture to Chilean folklore is expressed. Rodolfo Lenz, as editor of this text, presents himself as the linguistic and editor the leads the reading of Manquilef's central text, presenting it as the useful raw material for form Chilean national identity.

Keywords: Manquilef, Lenz, paratexts, folklore.

Recibido: 18/05/19 Aceptado: 01/07/20

\section{INTRODUCCIÓN}

El periodo histórico en que Rodolfo Lenz arribó a Chile se caracterizó por la creciente promoción de un espíritu nacionalista, cristalizado en distintas construcciones discursivas del Estado chileno, que buscaron la hegemonización en todo ámbito del territorio. La anexión total del territorio mapuche lograda en la década de 1880 por parte del ejército chileno implicó también la búsqueda de una solución cultural, social y política con respecto a la población que allí habitaba. Una estrategia que se utilizó para esto -además de la educación y la evangelización- fue la de procurar asimilarla a través del conocimiento científico y de lo que podríamos llamar la museificación de las culturas indígenas.

Esta necesidad de asimilación de la cultura y lengua indígenas, específicamente la mapuche, ya había sido anunciada décadas antes por intelectuales como el chileno Miguel Luis Amunátegui o el argentino Juan María Gutiérrez (Pas 2012), quienes procuraban integrarlas en el proceso de formación de un patrimonio cultural nacional propio, que contribuyera con nuevos imaginarios útiles al afianzamiento de las nuevas repúblicas después de un primer periodo postindependencia, que en el caso chileno, entre 1820 y 1840 , se caracterizó por la inestabilidad social y política ${ }^{2}$. Durante

\footnotetext{
2 En este texto, Hernán Pas nos dice que alrededor del 1850 "durante la etapa de consolidación del nacionalismo criollo - etapa que coincide, a grandes rasgos con el auge de las ideas románticas en todo el continente- la preocupación letrada se concentró en la consolidación de los patrimonios, aquellos bienes "ancestrales" pertenecientes a una etapa prehistórica -en el sentido hegeliano-, se diría casi edénica o mitológica, que la conquista primero, y la colonización después habían des-naturalizado y convertido, indignamente, en meras piezas arqueológicas" (Pas 2012: 76). El autor advierte que este cambio ideológico
} 
el periodo entre 1840 y 1860 Chile fue unos de los países que, producto de la prosperidad económica, "más tempranamente organiza el estado con una clase dirigente que a pesar de las diferencias entre sectores liberales y conservadores compartía la voluntad de orden y de gradualidad en las formas de participación ciudadana y asignaba un lugar importante al desarrollo de la educación y a la expansión de la cultura escrita" (Arnoux 2008: 9).

Las propuestas de los intelectuales anteriormente nombrados se proyectaron discursivamente hacia finales del siglo XIX como supuestos ideológicos que incluso son asumidos por la historiografía oficial chilena. De esta manera, vemos cómo Diego Barros Arana expresa en su Historia Jeneral de Chile (1884-1902) en el capítulo "Caracteres principales de la lengua chilena" algunas ideas sobre la lengua mapuche:

Si el vocabulario de esta lengua es incompleto y deficiente, si carece de voces que representen ideas genéricas o abstractas, como debe suponerse de todo idioma que no ha sido cultivado por una nación civilizada, puede suplirse en parte esta falta por medios sencillos. Las derivaciones de palabras se hacen con la mayor regularidad y por procedimientos casi invariables, formando de un sustantivo, por ejemplo, un verbo para denotar la acción, y de éste el nombre del que la ejecuta. Pero hay, además, otros medios de componer vocablos o de modificar el significado de los que existen. La lengua chilena pertenece a la familia de las lenguas aglutinantes o polisintéticas, que por una simple yuxtaposición de los elementos que se hacen entrar en la formación de las palabras, modifican su valor gramatical o le dan un sentido más o menos diferente para apreciar los diversos matices de una idea. (Barros Arana 1884/1999: 50)

La descripción de Barros Arana se basa en supuestos procedentes de la lingüística moderna, sobre todo la de origen germánico. Como podemos apreciar, todo queda en un grado de suposición ("como debe suponerse de todo idioma que no ha sido cultivado por una nación civilizada") y se recurre a la clasificación tipológica de las lenguas dada por Wilhelm von Humboldt (1988 [1836], ver Errington 2008: 76) 3 diciendo que "la lengua

se da en un momento en que la "fábula identitaria promovida por la independencia había comenzado ya a perder eficacia política y la necesidad de los Estados-nación de explorar y explotar recursos naturales tornaba inevitables los conflictos en las zonas interiores fronterizas". (Pas 2012: 76).

Von Humboldt desarrolló una tipología gramatical en la introducción de su obra, traducida al inglés como On language: the diversity of human language structure and its influence on the mental development of mankind (Von Humboldt 1988 [1836]). Allí distingue cuatro tipos de gramáticas que corresponden a una jerarquía de las lenguas según un supuesto 
chilena pertenece a la familia de las "aglutinantes o polisintéticas". Pero lo más importante en el párrafo citado es notar cómo el historiador al denominar "lengua chilena" a la lengua mapuche e "indios chilenos" a los habitantes que vivían en el actual territorio dominado por la república Chile antes de que este se configurara como tal, hace propia de lo chileno esa lengua y esa cultura, y posibles ciudadanos a esos sujetos hablantes de esa lengua y partícipes de esa cultura o, mejor dicho, sus descendientes.

Lenz compartía y difundía las ideas a las que hace referencia Barros Arana. En "La Lingüística Americana, su historia y su estado actual", publicado por ambos en 1893, nos dicen respecto al desarrollo de la lingüística en el continente americano: "si no se ha llegado propiamente a establecer principios que puedan considerarse definitivos, se ha conseguido al ménos reunir una crecida masa de hechos, i fijar ciertas ideas capitales que servirán de base para adelantar la investigación" (Barros Arana, Lenz 1893: 895). La identificación de la mirada del especialista con la perspectiva colonial es clara y sin fisuras: "El estudio de las lenguas americanas [se inició] el mismo día en que los europeos pisaron el nuevo continente" (ibíd.), asumiendo, de esta manera, la exclusividad europea de este saber y la imposibilidad de reflexión y conocimiento sobre la lenguas americanas utilizando las propias lenguas americanas. Diez años después de que Barros Arana comenzara a publicar su obra magna, Lenz iniciaría en los Anales de la Universidad la publicación de sus Estudios Araucanos (1894 -1897), donde valida las hipótesis sobre la lengua mapuche del historiador.

Asimilar la cultura mapuche era necesario para los intereses del Estado chileno, y también de una economía colonial de las lenguas, en cuya gestión participan las modernas ciencias del lenguaje ${ }^{4}$. En su nombre Lenz se entrega

grado de evolución. Joseph Errington (2008) nos dice respecto al discurso de Humboldt, que este distingue las lenguas cuyas palabras consisten en elementos aislados, como el chino, eran consideradas como lenguas "aislantes", "sin estructura gramatical”, y según su parecer como esencialmente defectuosas en tanto medio para la expresión intelectual; otras lenguas, muchas de ellas habladas en Norteamérica, combinan palabras para crear palabras más complejas, con gramáticas que Humboldt llamaba "aglutinantes"; un tercer grupo de lenguas, representado por el vasco, tienen gramáticas a las que llamaba "incorporativas" o "polisintéticas", para describir el modo en el que fusionan palabras en totalidades indivisibles equivalentes a oraciones completas; en la cuarta categoría, situaba las lenguas que consideraba de "primer orden": aquellas que poseen gramáticas flexivas.

4 Juan Ennis aclara cómo el papel que desempeña la filología en el avance de un modelo de economía globalizado contempla la inclusión del otro: "ese impulso de inclusión no excluye la fijación de jerarquías, sino que por el contrario las hace posibles: se trata de la incorporación del otro como material bruto en una economía, un sistema de gestión, archivación, asignación de valores y consecuentemente de roles. El movimiento es democrático y colonial, al 
con pasión a esta tarea de hacer de la lengua y la cultura mapuche parte de la narrativa de lo chileno, apropiándose de ella a través de la reunión y lectura de su documentación.

La noción de hegemonía tal como la propusiera Gramsci se ha revelado especialmente eficaz en el estudio del discurso social del cual nos ocupamos aquí en su relación con una forma precisa del discurso científico. Marc Angenot otorga así un lugar preeminente a la categoría, identificando en ella a grandes rasgos "las dominancias interdiscursivas, las maneras de conocer y de significar lo conocido que son lo propio de una sociedad, y que regulan y trascienden la división de los discursos sociales" (2010:28), que puede observar el investigador. Por otra parte, tendremos en cuenta en esta investigación la perspectiva de Raymond Williams de una hegemonía adaptativa como "cultura que debe ser considerada asimismo como la vivida dominación y subordinación de clases particulares" (Williams 1988: 131-132). En este sentido lo hegemónico no debe comprenderse como algo rígido: si bien tiene sus límites, estos siempre son sometidos a presiones específicas y cambiantes. Finalmente, tendremos también en cuenta las reflexiones acerca de la relación entre lengua y hegemonía que esboza Diego Bentivegna en su estudio preliminar a los escritos de Gramsci sobre el lenguaje, donde plantea la necesidad de pensarla en términos de conflicto sobre lo que se considera una cultura legítima respecto a lo universal, lo nacional y lo regional, y se ocupa asimismo de aclarar el carácter isomorfo de la relación entre las lenguas 5 .

Vemos cómo se comienza a conformar una hegemonía de lo decible y aceptable dentro de la sociedad chilena de una época respecto al tema mapuche, tema que estaba presente desde la fundación de la república y que se hizo más recurrente en el momento en que se comenzó con la llamada

mismo tiempo, sin contradicción. Incluye la lengua y la cultura del otro apropiándosela. Constituyéndose en su interprete y mediador, asignándole su valor y forma última" (Ennis 2016: 125).

5 En palabras del autor: "la relación entre las lenguas en una situación histórica determinada no son relaciones que reflejan las relaciones sociales, pues implicarían una escisión entre las lenguas y lo político, entre lenguaje y poder, que precisamente, la intervención de Gramsci intenta impugnar. Nos hallamos, por el contrario ante relaciones isomorfas -ni de reflejo, ni de representación- entre las dinámicas del resto de lo social, que pone en primer plano la capacidad de unificación de un área geográfica a partir de las operaciones de fuerzas de integración que van más allá de las fuerzas emanadas estrictamente del estado" (Bentivegna 2013: 46). Intentaremos mostrar cómo funcionan estas fuerzas de integración en este caso encarnadas en la ciencia lingüística y etnográfica. 
Pacificación de la Araucania ${ }^{6}$. Este trabajo pretende investigar sobre algunas nociones de lo hegemónico dentro de la sociedad chilena respecto a cómo se incluyó dentro del orden patrimonial a la lengua y la cultura mapuche a partir de la instauración en Chile de la filología, la lingüística y la etnografía. Se intentará dar cuenta de este proceso de apropiación del mundo mapuche y los supuestos ideológicos que subyacen en sus enunciados analizando el discurso de Rodolfo Lenz inscrito en los paratextos a los Comentarios del Pueblo Araucano de Manuel Manquilef publicado en 1911. Tomamos la definición de paratexto del libro Umbrales de Gerard Genette (2001), que los define como aquellos elementos que acompañan al texto principal: "cierto número de producciones, verbales o no [...] que sirven para darle presencia, para asegurar la existencia en el mundo" (Gennette 2001: 7). Estos elementos son una frontera borrosa entre el adentro y el afuera del texto, y sirven para guiar la lectura de la obra. Los paratextos, específicamente los peritextos (Genette 2001: 10), a los que se hace referencia -título, prefacio, introducción, etc.- en este trabajo se sitúan temporalmente en el momento de aparición de la edición de la revista de la Sociedad de Folklore de Chile (de ahora en adelante SFCh). También incluiremos el análisis de un epitexto, paratexto que se encuentra "alrededor del texto todavía, pero a una más respetuosa (o más prudente) distancia", más precisamente, "todos los mensajes que se sitúan, al menos al principio, en el exterior del libro" (Genette 2010: 10). Se trata del Programa de dicha Sociedad, redactado por el propio Lenz y publicado en 1909.

Los Comentarios del Pueblo Araucano (La Faz Social) fueron leídos por primera vez en la sesión del 9 de octubre de 1910 de la SFCh, publicados en el tomo II de la revista de dicha institución en el año 1911 e impresos por la editorial Cervantes. Este texto aparece enmarcado con una serie de paratextos destinados a dirigir la lectura de quienes se interesen en él, sobre todo a los interesados en este nuevo campo de conocimiento que Lenz funda en Chile: el estudio del folclore. Dicho campo, y la SFCh en particular, se interesaba en el estudio de la identidad del pueblo chileno, por lo que se apropian de una parte de la cultura mapuche, aquella que podía ser aprovechada como un antecedente de la nación chilena, que por ese tiempo cumplía 100 años desde su independencia. Este aniversario fue el motivo por el que se realizó el concurso convocado por la SFCh, en el que Manquilef obtendría el primer lugar con sus Comentarios. Los paratextos que rodean el texto principal no

\footnotetext{
6 Paralelamente en Argentina se vivió un proceso similar con la llamada Conquista del desierto, también una campaña militar que anexó parte del territorio mapuche de la Pampa y la Patagonia al de la república Argentina.
} 
solo cumplen la función de orientar y controlar la recepción de un texto etnográfico y lingüístico de una cultura y una lengua que era considerada exclusivamente oral por la ciencia de ese momento, sino que también eran el marco teórico que controlaba y dirigía esa escritura.

Así, al observar cómo el orden de lo hegemónico en Chile a fines del XIX incorpora la lengua y cultura mapuche como representación, como bien patrimonial -es decir, cómo en el ámbito del discurso se constituyen las prácticas significantes, de lo decible o escribible--, nuestra investigación apuntará a rastrear cómo el trabajo del lingüista contribuyó, por una parte, a la objetivación y/o reducción del mapuche y lo mapuche dentro de la cultura chilena, y, al mismo tiempo, a empujar el límite de lo hegemónico para hacer posible y deseable dicha asimilación?

El ethos del lingüista centroeuropeo, como portador de una maquinaria de conocimiento científico, crea un mito en torno a la cultura y la lengua mapuche separándola del propio pueblo que la vivía y la hablaba. Esta mitología la entendemos en los términos planteados por Barthes (1957/1980), cuando asevera que "la mitología sólo puede tener fundamento histórico, pues el mito es un habla elegida por la historia: no surge de la 'naturaleza' de las cosas" $(1980,108)$. En este caso son las necesidades históricas de la geopolítica de un país, la anexión del territorio mapuche $-\mathrm{y}$ los del norte luego de la guerra del Pacifico-al de la República de Chile y las necesidades discursivas derivadas de la Historia Jeneral de Chile, las que conducen a validar el imaginario creado sobre el pueblo mapuche. Pero también era necesario separarlo de "lo chileno", de lo criollo, situando al mundo mapuche en lo premoderno, en la prehistoria de Chile, como el residuo de una supuesta raza incivilizada ${ }^{8}$.

En el caso de Manuel Manquilef, podríamos decir que fue presentado como el modelo de sujeto indígena asimilado al que la sociedad moderna chilena aspiraba: un hijo de padre mapuche "cacique" y de una madre chilena "cautiva" que conoció por su abuela paterna la lengua y la cultura mapuche, para luego ser educado en las instituciones occidentales, conociendo allí

En este punto hay que recordar que Lenz tuvo una relación polémica con algunos sectores de la intelectualidad chilena más conservadores, que veían su interés por el habla popular chilena y por el idioma mapuche con bastante recelo ya que significaban una ampliación de lo hegemónico que ellos no aceptaban. Ver la polémica que tuvo con Eduardo de la Barra en Pavez (2015), Velleman (2007) y Altschul (2012).

8 Uno de los recursos para lograr esto, por ejemplo, fue tratar al mapuche contemporáneo al tiempo de la enunciación del discurso de Lenz como disociado de su pasado, es decir, ya no se le trata como tal sino como "descendiente de". 
la lengua castellana y la cultura chilena. Según José Quidel (2015) en su artículo, originalmente escrito en mapuzugun y traducido al español como "Del por qué y cómo fueron violentados y sobrepasados los mapuches en su pensamiento y espiritualidad"; la primera institución educativa destinada a la comunidad mapuche fue el Colegio de Naturales, fundado en el año 1777 en Santiago y trasladado en 1786 a Chillán. Esta institución "fue creada para buscar la forma de detener la matriz del pensamiento mapuche que aún sobrevivía" (Quidel 2015: 48). Este colegio y otros dispositivos educacionales se establecieron en la llamada Frontera, zona de contacto ${ }^{9}$ entre el mundo mapuche y el mundo winka, y eran lugares donde "los hijos de los logko aprenden del conocimiento winka, entonces más adelante estos mismos jóvenes podrán diseminar ese conocimiento. De esta forma se termina la cultura mapuche" (Quidel 2015: 49).

\section{REPRESENTACIONES SOCIALES, IDEOLOGÍAS LINGÜÍSTICAS E IDEOLOGEMAS}

Mariana di Stefano, en su trabajo El lector libertario (2013), reformula una serie de conceptos del campo del análisis del discurso y la sociología, articulándolos con otros propios de la glotopolítica, que resultan operativos no solo para su objeto de estudio, sino también para otros contextos, como el que aquí estamos analizando. Apoyándonos en su propuesta, y recurriendo en ese sentido a las herramientas que nos da el análisis del discurso y asumiendo un punto de vista glotopolítico es que queremos avanzar sobre el análisis de este corpus paratextual, prestando especial atención a los ideologemas allí articulados.

9 Mary Louise Pratt define la zona de contacto como: "Espacio de encuentros coloniales, el espacio en el que las personas separadas geográfica e históricamente entran en contacto entre sí y entablan relaciones duraderas que por lo general implican condiciones de coerción, radical inequidad e intolerable conflicto. Aquí el termino contacto ha sido tomado de la lingüística, en la que la frase lengua de contacto se refiere a lenguajes improvisados que se desarrollan entre hablantes de distintas lenguas que necesitan comunicarse continuamente, por lo general dentro del contexto de las relaciones comerciales" (Pratt 2010: 33). En este trabajo se considera la llamada Frontera, actual VIII y IX región del territorio chileno, como una zona de contacto. 
Un primer concepto que nos interesa es el de "representaciones sociales", que son sistemas de valores, de nociones y de prácticas, a través de los cuales se percibe el mundo y se elaboran respuestas. Según Bourdieu (1987), las representaciones sociales son un componente del habitus ${ }^{10}$, que es a su vez un esquema de percepción de lo real y un dispositivo para la acción, que expone las divisiones del universo social a la vez que contribuye a establecerlas. Tienen un valor práctico, que tiene que ver con la construcción de una realidad común al conjunto social. Las representaciones también participan en la definición de la identidad de un individuo y de un grupo social, lo cual permite su ubicación dentro de la heterogeneidad de una sociedad.

Una de las formas de construir las representaciones sociales es a través de representaciones del lenguaje que son, a su vez, vehículo de ideologías lingüísticas. Estas últimas son entendidas como:

ideas que integran nociones del lenguaje, el habla o la comunicación con visiones y acciones concretas que afectan la identidad lingüística de una determinada comunidad. El funcionamiento de estos sistemas de ideas se analiza siempre en el contexto de las estructuras sociales, relaciones de poder y actividades políticas y económicas relevantes para el conocimiento humano estudiado. (Del Valle 2005: 399).

De esta forma, los valores atribuidos a una lengua implican también una valoración de las colectividades que la hablan.

Para lograr una descripción del funcionamiento de la ideología en los textos a analizar proponemos recurrir al análisis de los ideologemas. Este concepto, propuesto también por Angenot en su libro La parole pamphletaire (1982), reformula el concepto de topos de la antigua retórica. Para él, ideologema es la máxima ideológica que subyace a un enunciado, los supuestos que son aceptados por los interlocutores. Son máximas que pueden estar explicitadas o no, no necesitan demostración y son útiles para validar y legitimar un determinado campo. Su análisis consiste principalmente en identificar los supuestos en los que se apoyan los enunciados y que configuran una determinada ideología y su papel en la formación de representaciones sociales (Di Stefano 2013: 22).

10 Según el autor, son "estructuras mentales a través de las cuales aprehendemos el mundo social, son en lo esencial el producto de la interiorización de las estructuras del mundo social. Como las disposiciones perceptivas tienden a ser ajustadas a la posición de los agentes, aun los más desventajados, tienden a percibir el mundo como evidente y a aceptarlo mucho más ampliamente de lo que podría imaginarse, especialmente cuando se mira con el ojo social de un dominante la situación social de los dominados" (Bourdieu 1987: 134). 


\section{ANÁLISIS DE CORPUS}

Los paratextos que preceden al texto de Manquilef son:

1. Portada.

2. "Prefacio" firmado por Rodolfo Lenz.

3. Una autobiografía del autor titulada: "Manuel Manquilef" y debajo de este nombre aparece el subtítulo "(su descendencia y educacion)". Dentro de este, un elemento paratextual importante de carácter iconográfico; un retrato fotográfico de Manquilef.

4. Luego aparece el título del texto, "Comentarios del pueblo araucano (La Faz Social)", bajo el cual se consigna el subtítulo "Origen de este trabajo". No figura el nombre del autor pero las convenciones del género permiten suponer que se trata del director de la SFCh, es decir Lenz.

5. "Dedicatoria".

6. "Introduccion", firmada por Manquilef.

7. "Esplicación de la escritura mapuche", en mayúscula con el tamaño de las fuentes un poco más pequeño y también en mayúscula: "Para el que lea la parte mapuche".

8. Epígrafe.

Un total de ocho elementos paratextuales, textuales y uno iconográfico, que ocupan un total de 17 páginas, más la portada. Tres de estos paratextos fueron escritos por Lenz y tres por Manquilef, mientras el epígrafe es una doble cita de Lenz. El formato original de este texto es el de revista o cuadernillo. Finaliza con una "nota" de dos páginas donde Lenz incluye un glosario con palabras chilenas y mapuches, y una explicación del nombre de Manuel Segundo Manquilef.

Teniendo en cuenta solo estos elementos formales podemos decir que cuantitativamente los paratextos ocupan un tercio del folleto, que tiene un total de 58 páginas. El modo en el cual la escritura que lleva la firma de Lenz se dispone en torno de la de Manquilef permite pensar que esta se encuentra cercada por aquella. De este modo, tampoco queda lejos la conjetura de que la disposición estratégica en el espacio de lo simbólico en el libro no deja de reproducir, en cierta manera, la forma de la política reduccional que el Estado chileno aplicó con el pueblo mapuche reduciendo su territorio a una mínima parte.

Por ahora analizaremos solo algunos de estos paratextos. 


\subsection{LA PORTADA: SU DISPOSICIÓN GRÁFICA, EL TÍTULO DE LA OBRA Y AUTORÍA}

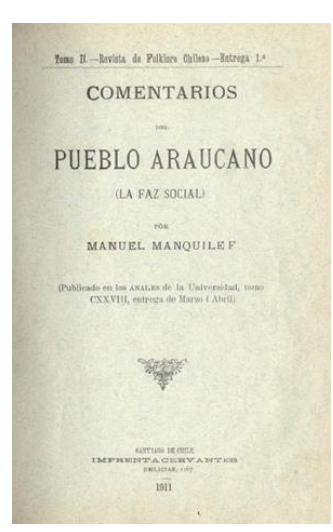

Es importante considerar este elemento paratextual para entender cómo la escritura de un texto de una lengua que es considerada oral entra en circulación como impreso en la sociedad chilena. Desde su título Comentarios entendemos que se tratará de una explicación u opinión sobre el pueblo araucano. Pero al usar la contracción del se entiende que el que hace el comentario no es una persona ajena sino alguien perteneciente al propio pueblo araucano, ya que hay una cierta ambigüedad del genitivo, dándose a entender que es el propio pueblo araucano quien realiza los comentarios sobre el pueblo araucano. A esto se agrega un subtítulo entre paréntesis, la faz social, que sería -siguiendo a Genette (2001: 52) - una indicación genérica que diría que se trata de un texto etnográfico, de carácter científico. Esta indicación de género está explicitada en la parte superior de la portada donde se indica que este cuadernillo es parte de la Revista de Folklore Chileno, órgano de difusión de la SFCh. Entre paréntesis bajo el título se muestra de igual manera que este texto fue publicado con anterioridad en los Anales de la universidad, "tomo CXXVIII, entrega de marzo y abril". Esto es, en la publicación científica más importante de su tiempo dentro de Chile.

También el nombre que figura como autor -como sujeto al que se le atribuye la unidad y coherencia de una obra (Chartier 1999)- da credibilidad al título ya que por su apellido da cuenta de que se trata de una persona mapuche, y que por lo tanto puede hablar por dicho pueblo con propiedad. Es más, se presenta como la voz de ese pueblo. Por esto es que se dice que el texto de Manquilef es el primero en su tipo: es la primera vez que el apellido de un mapuche aparece en el lugar del texto destinado al nombre del autor. Si bien antes habían aparecido en el interior de los textos como informantes, nunca habían aparecido en la portada de un escrito.

\subsection{Prefacio}

Este prefacio está firmado en Santiago el 5 de abril de 1911, es el paratexto escrito más próximo en tiempo al momento de su publicación. 
En la primera página Lenz escribe que este texto "reviste un interés particular por ser de absoluta novedad", ya que "[e]s la primera vez que un descendiente inmediato de la heróica raza cantada por Ercilla, un jóven que en su infancia no ha hablado otra lengua que la mapuche, publica una obra científica" (Manquilef 1911: 3). El comentario de Lenz hace referencia a un imaginario instalado desde la independencia, que consagra la valentía del guerrero mapuche como parte del relato de la identidad nacional chilena, y ello a través de la lente que ofrece el poema de Ercilla, consagrado por Andrés Bello como poema épico fundacional de la nación chilena ${ }^{11}$. Esta fue la base para que la intelectualidad de la segunda mitad del siglo XIX fuera configurando un discurso sobre lo que era la "raza chilena": un producto del cruce de españoles y mapuches en el marco de un conflicto bélico. Según lo expresa el propio Lenz (1897) "es una de las causas para la fuerza superior de la nación chilena" (Estudios Araucanos, XIII) ${ }^{12}$.

Por otro lado, se resalta el hecho de que el sujeto es un "joven" que en su "infancia" solo habló la lengua mapuche. Es decir, ese sujeto ahora habla la lengua castellana y además puede dar cuenta de su lengua madre: la lengua mapuche. Y para ello además cuenta con el método científico que esta persona adquirió al ser formada en las instituciones educativas occidentales. En este enunciado se presenta el ideologema del mapuche como más civilizable que el resto de las etnias de América. Lenz consideraba al mapuche superior respecto a otros pueblos americanos: "por esta i otras razones creo yo que los araucanos son mas capaces de civilizarse que la mayor parte de los indios americanos" (Lenz 1897, XIV).

Continúa el prefacio:

11 "La araucana, La Eneida de chile, compuesta en Chile, es familiar a los chilenos, único hasta ahora de los pueblos modernos cuya fundación ha sido inmortalizada por un poema épico" (Bello citado por Ennis 2015: 122).

12 Otros intelectuales contemporáneos sostenían este tipo de tesis, como Nicolás Palacios, que en su libro Raza Chilena (1904), atribuye el valor de esta supuesta raza a su origen "araucano". Sin embargo, hay matices que deben ser tomados en cuenta. Lenz había expresado en el discurso leído en el congreso científico chileno y reproducido en los paratextos de los Estudios araucanos (1897), su propio visión sobre la formación de la nación chilena. Según Lenz la nación chilena se formó por "la inmigracion continua de nuevas fuerzas militares, las que aquí mas que en ninguna otra parte de América fueron requeridas por la resistencia tenaz de los indios. De esta suerte los araucanos fueron la causa directa de la concentración especialmente fuerte de españoles que tuvo lugar en Chile i que es una de las causas para la fuerza superior de la nacion chilena" (Lenz 1887, XIII). Se resalta la fuerte presencia del inmigrante europeo en territorio nacional como la causa de la "superioridad", no la mezcla con el mapuche. 
es verdad que mas de una vez, relaciones y descripciones de costumbres i otras noticias interesantes debidas a la pluma de Manquilef han visto la luz por medio de la imprenta, incorporadas en las importantes obras que el sabio i asíduo etnólogo don Tomas Guevara ha publicado con el título "Psicología del Pueblo Araucano" (1908) i "Folklore Araucano" (1911). Pero en esas ocasiones el indio no habia sido más que colaborador de su maestro. Hoy se presenta solo en la arena. (Manquilef 1911: 4)

En este enunciado se nos presenta una metáfora importante de la cultura de la época: las cosas ven la luz, son conocidas por el resto, cuando son publicadas en papel impreso. Es por este medio que "la pluma de Manquilef" es vista. Es decir, según esta metáfora toda esa información de "relaciones" y "costumbres" de los pueblos originarios antes se encontraba en la oscuridad. En este sentido adquiere una importancia clave el hecho de que Manquilef, a diferencia de otros integrantes de su pueblo, maneja la escritura, y su calidad de escriba es denotada por el término "pluma". En este punto se puede establecer también otra significación de la palabra "pluma" como referencia al estereotipo del "indio" norteamericano al que ya en ese tiempo se lo representaba en las expresiones de cultura popular con una pluma en la parte posterior de la cabeza. Por otro lado, se establece una relación de subalternidad entre el informante mapuche -Manquilef y su pluma- y el winka al que se le llama "sabio i asiduo etnólogo don Tomas Guevara", quien ya tiene unas cuantas publicaciones sobre el tema y gracias a cuya mediación se pudieron conocer los escritos de Manquilef, que es resaltada al utilizar las nominalizaciones "indio", para denominar al subalterno y "maestro" para el europeo ${ }^{13}$. Pero en este caso se trata de un Indio Inteligente, otro ideologema que suponía que no todos los sujetos del pueblo servían para dar cuenta de su cultura, sino los sujetos que manejaban el idioma mapuche y el castellano.

Al lingüista no le interesa la autoridad o la forma de saber tradicional mapuche, desprecia la forma en que se transmite el saber dentro de la cultura subalterna, respecto a cuyas autoridades nos dice en la introducción a sus Estudios Araucanos: "también he encontrado a individuos intratables que apenas soltaban alguna que otra palabra; i la mas porfiada fué aquella machi, una médica, verdadero tipo de bruja, que visité en su ruca cerca de Mininco.

13 Jorge Pavez (2003-2015) ha hecho una importante investigación y reflexión sobre la relación entre los etnógrafos e indígenas en su libro Laboratorios etnográficos, los archivos de la antropología en Chile (1880-1980). A partir de un trabajo de archivos nos plantea cómo se establecen relaciones de subalternidad entre los etnógrafos y en general todos los científicos, europeos en su mayoría, que se dedicaron a estudiar la lengua y las culturas originarias y los informantes indígenas. 
Doña Manuela comprendia muy bien lo que queria yo, pues hablaba el castellano como cualquier mujer del pueblo; pero cuando le dirijia preguntas concretas me contestaba con un conjunto indisoluble de palabras indias de las cuales no podía apuntar nada; i cuando le manifesté mi desesperacion, dijo con un jesto que no podia ménos que comprender, dirijíendose a uno de sus clientes: “imala cabeza!”” (Lenz 1894 -1897: XVI). El mapuche que no sirve bajo la lupa del científico, es aquel que se aferra a sus tradiciones ancestrales y al sistema de valores que garantiza su pervivencia, en este caso una persona que dentro de su cultura está investida con la autoridad religiosa y medicinal: la machi. Ella se niega a seguir el ritmo que necesita el lingüista para trascribir lo que le dicen, y vuelve la cara para comunicarse con aquellos sujetos que comparten su cultura ${ }^{14}$.

Lenz concluye el párrafo con una metáfora referida a Manquilef que, siguiendo los planteamientos de Lakoff y Johnson (1980), llamaremos estructural en relación a la cultura escrita del siglo XIX y comienzos del siglo XX: "hoy se presenta solo en la arena". La palabra arena representa en primera instancia el espacio público, más precisamente el de la cultura impresa, donde ya subrayamos la novedad de la aparición de la firma de Manquilef. Pero al mismo tiempo, la palabra nos remite en este contexto también a la imagen del circo, el espectáculo popular por antonomasia en la época. Se presenta de esta manera una doble significación del espacio público: por una parte el espacio público culto del ensayo académico impreso, en este caso etnográfico; y por otro lado, el espacio público popular del circo, donde la pluma remitía con claridad también a la alteridad indígena. Esta significación posible del término se articula bien con una cierta espectacularización de aquello que este aparato paratextual envuelve o cerca. En esta arena, la cultura y lengua mapuche, exhibida por el sujeto Manquilef, se ve reducida a la lógica del espectáculo, y así de una mercancía que ya no tiene un valor de uso en cuanto cultura vivida por un grupo humano, sino en tanto es exhibida a un público consumidor. Esta relación entre cultura y exhibición es crucial a la hora de definir el valor de lo que se considera cultura o no.

14 El contraste entre la función asignada en la comunidad a el o la machi, como encargada de la salud corporal y espiritual de la comunidad, traducido como "medica" y el juicio que Lenz emite sobre "doña Manuela", "verdadero tipo de bruja", contribuye a reforzar el lugar anómalo de aquella que se niega a cumplir el rol de informante, subrayando su absoluta alteridad y relegada al ámbito de la superstición en contraposición al saber científico. Además de todos los juicios que admite en la tradición europea el nombre de "bruja" relacionado con el género femenino, la maldad, la tradición, la autoridad y el saber legítimo. 
La escena que describe Lenz indica el carácter inaugural que encuentra en el texto etnográfico. Pero además requiere una transacción: una 'oferta' de parte de Manquilef como potencial sujeto portador de un saber y una 'demanda' de Lenz a Manquilef de exhibir su infancia por escrito (autoetnografía) como necesario para poder dar un sentido al ensayo y también ser parte de la SFCh. De esta manera, continúa el texto en el siguiente párrafo, escrito en primera persona: "por esta razon pedí al señor Manquilef, que se habia ofrecido como miembro de la sociedad de Folklore Chileno, que nos diera una breve autobiografía" (Manquilef 1911: 4). Lenz se muestra como el editor del texto que presenta, refiriéndose al presentado Manquilef al que, por sus características étnicas, le pide que exponga su vida por escrito. Pero antes de esta petición se resalta que el propio autor mapuche se había ofrecido para participar de una organización dedicada al estudio del folclore de Chile. Lo que implica que este sujeto mapuche se considera a sí mismo como representante de dicha nación y que por eso su autobiografía fue presentada en la revista de la SFCh. Es importante el epíteto de señor en tanto le da un estatuto que antes no se le había dado, las anteriores referencias al sujeto, primero fueron su características biográficas y luego "Manquilef y su pluma". En este caso el recurrir al epíteto "señor" implica una mayor individualización y respeto.

Según Lenz, el trabajo que se presenta en esa edición, "siete capítulos de 'la Faz Social del Pueblo Araucano', no necesita recomendación”. E interpela al lector con la pregunta: "¿Qué fuente mas intachable podemos desear para conocer la etnolojía i folklore mapuche que las descripciones dadas por un hijo de la misma nacion?". En este enunciado, al referirse a nación, Lenz lo hace en un sentido más restringido, pensando en lo que hoy se denomina "etnia"15. En el sentido hoy más extendido del término, se presupone que la nación mapuche es parte de la chilena, ya que es presentado en la revista de la SFCh. Este ideologema es una estrategia para asimilar y hacer parte

15 En los estatutos de la Sociedad de Folklore Chileno de 1909 se nos dice que este es "una rama de la etnolojia", que es la ciencia que "investiga las leyes de la formacion humana con el objeto de presentar un cuadro de su vida síquica. No se ocupa de lo que piensa el individuo, sino en lo que piensan los pueblos como colectividad, lo que Bastian, el verdadero fundador de la etnolojia moderna, llamo idea étnica. Sólo el hombre como «ser social», como producto de la cultura i de la sociedad que lo rodea, es el objeto etnolojía. Como no se puede negar que todos los hombres tienen esencialmente las mismas calidades físicas i fisiolójicas, asi también en todas partes, en todas las época los mismos rasgos. Asi tambien sienten y piensan, aman i odian en forma parecida, forma que naturalmente varia un poco segun la raza y el medio ambiente". Recalcando sobre todo la necesidad de estudiar "los actuales pueblos naturales, i de baja civilización [ya que] presentan claras imajenes de lo que han sido los pueblos mas civilizados de hoy en la época de las tinieblas de prehistoria”. (Lenz 1909: 5). 
del patrimonio nacional de Chile el pueblo y la cultura mapuche, lo que necesariamente pasa por una alienación en tanto no interesa la comunidad de sujetos vivientes sino como espectáculo exhibido en la escritura. Lo mapuche, sea como nación, como cultura o como idioma es considerado por el lingüista en tanto era el antecedente -o el sustrato en el caso de la lengua- de lo chileno.

Los siguientes dos párrafos se centran principalmente en el problema de la traducción. En ellos Lenz es crítico con la traducción realizada por Manquilef y advierte al lector occidental especializado: "el lingüista que no rehuya el trabajo de la comparación comprenderá cómo Manquilef lucha a veces para encontrar una expresion adecuada en castellano para lo que en su concepto espresa la frase india" (Manquilef 1911: 4). Sin embargo, por ahora nos centraremos en el análisis de la autobiografía del autor mapuche para dejar el problema de la traducción y la concepción lenziana de esta para un capítulo más amplio ${ }^{16}$.

\subsection{UNA AUTOBIOGRAFÍA: FORMACIÓN DE "MANUEL MANQUILEF (SU DESCENDENCIA Y EDUCACION)"}

Esta autobiografía aparece firmada en Temuco el 30 de mayo de 1910.

Bajo este subtítulo Manquilef escribe su autobiografía hecha por petición de Lenz, según se expone en el prefacio. Allí hace referencia a su origen poniendo en primer lugar su procedencia geográfica, "la revoltosa comarca de Makewa", y su fecha de nacimiento, 1887. Se establece de esta manera su ubicación de origen dentro de la zona de contacto, lugar que es calificado como revoltoso, por lo que podemos suponer que en dicho territorio aún se generaba cierta resistencia a la dominación del Estado chileno. Continúa nombrando a sus progenitores, su padre "el cacique" y su madre "la cautiva chilena", nominalizándolos primero como apelativos de estereotipos antes que por sus nombres propios. En el caso del padre, Fermín Trekamañ Manquilef, por el nombre que los occidentales dieron a cualquier jefe de un grupo indígena que en lengua mapuche serían lonko o $\log k o$, y a su madre Trinidad González, denominándola con un sintagma,

16 Las reediciones en el presente siglo de la obra de Manquilef han hecho aparecer la llamada tercera columna (Menard 2006), donde se vuelve a traducir al mapuzugun (en este caso) el texto que aparece traducido al castellano del mapuzugun en la primera edición. Otros trabajos que se refieren al problema de traducción en Manquilef son los de Pavez (2005, 2015), Mallon (2011) y Payas (2015). 
una imagen que representaba el "abuso" de los "indios" con la civilización. Ambos apelativos son tópicos de esa época. La cautiva es un nombre que designa una condición de la mujer en tiempos coloniales, que es retomada para alimentar el imaginario de las repúblicas. Las cautivas eran mujeres de origen europeo o criollo que habían sido raptadas o entregadas por los españoles a los "indios" y tomadas por esposa por alguno de ellos, aceptaran ellas o no esta nueva condición ${ }^{17}$. Un hijo nacido de la relación consentida de un cacique y una cautiva es, en todos los casos, el mejor ejemplo del origen mestizo de la llamada "raza chilena".

Continúa Manquilef dando cuenta de su formación bajo la tutela de su abuela paterna, su "ayin kuku'", donde aprende la lengua, las costumbres y modo de vida del pueblo mapuche. Los párrafos que continúan adquieren un ambiente pastoril e idílico, donde se da énfasis a sus recuerdos remarcados en sintagmas como: "recuerdo frescamente las primeras representaciones de infancia", "jamás se olvidan i por eso nunca borraré de mi mente", "Frescos están los ratos agradables que pasé". Sus evocaciones dan cuenta principalmente de la cultura que en los momentos que rememora era asumida como propia y parte de su vida cotidiana: "la vez primera que mi ayin kukú, amada abuelita, me hizo cantar los lindos amorosos versos que ella me había enseñado, a la simpática Mecei, indiecita que hoy es machi i pasa por ser la mas bella de pelal" (Manquilef 1911: 5-6). También refiere su participación en las ceremonias propias de su pueblo: neikurewen, machitún, kamarikun. Nombra asimismo una serie de instrumentos (Kultrun, Trutruka, klarin y lolkiñ) que marcan el "son" de dichas ceremonias que le hacían "levantar alternativamente mis rodillas para bailar". Al denominar el "son" a la música y el "levantar alternativamente" para caracterizar el baile, remarca la simplicidad de estas expresiones propias del mundo mapuche. Al enumerar los purün o bailes -que adjetiviza como simples- que realizaban en dichas ceremonias, siempre lo hace primero en lengua mapuche, marcándolo en cursivas, y luego ofrece su traducción al castellano ("choike purun, baile de choique: tregulpurun, baile de queltehue. [...] Lonkomeu, baile de la cabeza"). Lo mismo pasa cuando nombra algunos ejercicios físicos y

17 Expresiones artísticas del siglo XIX dan cuenta de este imaginario. En literatura, el escritor argentino Esteban Echeverría escribió un poema que lleva ese nombre, publicado el año 1837; en la pintura, Angel del Valle realizó el cuadro "el regreso del malón” (1892), conocido popularmente como "La cautiva". Este fue expuesto durante largo tiempo en el escaparate de una importante ferretería ubicada en la calle Florida en el centro de Buenos Aires. Ambas expresiones, de alguna manera, en algún momento cumplieron un fin propagandístico que justificaba las campañas militares que unificaron el actual territorio del Estado-nación argentino. 
juegos como el paliñ y el nado, explicando los distintos nombres con que se designan objetos y personas en ellos como, por ejemplo, weyelkantufe, que es nadador. El marcar la lengua mapuche indica que su escritura está al servicio de la lengua castellana, el texto etnográfico es un artefacto para marcar el exotismo de una cultura que es propia del mismo territorio donde se produce y se publica.

Es importante en la presentación de todo el dispositivo textual la explicación de su nombre, Manuel Segundo Manquilef:

Ante todo, réstame decir que todos mis compañeros de juego sabían que era hijo de una chilena i como practicase las costumbres igual i, a veces mejor que ellos, designáronme con el apodo de Cheuntu, que quiere decir, el que se vuelve jente. De este modo, pues, viene el nombre de Segundo con que también se me bautizó. (Manquilef 1911: 6)

Su segundo nombre, Segundo, se explica primero por una adaptación por semejanza fonética del apodo mapuche al nombre castellano. Pero si sus iguales mapuche lo denominaron con ese nombre por su condición de mestizo y de persona en formación, su bautismo cristiano lo denominó "Manuel Segundo", adaptando no solo el apodo a la pronunciación castellana sino también la condición a que hacía referencia su apodo: el hacerse gente. Esta es la clave de lectura de este texto, la historia de la formación de un sujeto que en su primera infancia se forma como mapuche en el contexto de la vida de un lof o comunidad de un territorio ${ }^{18}$, y luego como chileno pasando por todas las instituciones de educación hasta llegar a ser profesor dentro de ese sistema educativo, dejando de ser mapuche o donde su vida mapuche solo queda en sus recuerdos.

El primer episodio de esta formación de Manquilef, y que representa, a nuestro juicio, la transición entre dos épocas es relatado en el texto:

permaneciendo una tarde a la orilla del fogon de mi ruka, teniendo a mi abuelita en mi frente i estando yo con mis piernas cruzadas raspando una papa para engullírmela con medkeñ (sal molida con ají); vi repentinamente a una señora con mi padre i que ánsias me contemplaban. La señora me hablo i yo corrí a las orillas de mi abuela sin entender una palabra que la chiñurra hablaba. Al dia siguiente se me condujo a una escuela pagada en donde permanecí tres meses, logrando huir furtivamente, al fin de

18 La noción de Lof se suele traducir como comunidad, pero es más que eso, ya que implica una territorialidad. 
ese tiempo, a mi tierra. En esta escuela aprendí a articular palabritas chilenas. (Manquilef 1911: 6)

Esta parte del relato nos da cuenta del choque de culturas y las distintas maneras de entender la educación o la formación de los niños. En el contexto cultural mapuche, la formación en la primera infancia de los niños generalmente es encargada a la abuela paterna que enseña alrededor del fogón en el interior de la ruka (construcción de vivienda). Ahí es donde se aprende la lengua, los relatos míticos, epew (relatos semejantes a las fábulas o cuentos fantásticos occidentales) y en general el patrón de conducta del mapuche bajo sus propios valores. Es de ese contexto que su padre, un Lonko (cacique) importante, junto a una chiñura (adaptación fonética mapuche del español señora) chilena, al parecer una profesora, arrancan a Manquilef para enviarlo a una escuela, donde aprende a "articular palabritas chilenas", y de la cual escapa en cuanto puede, una primera señal de resistencia al proceso de formación.

Con el "fin de que no huyese" se le lleva a una "escuela elemental de Temuco", donde permanece seis años y comienza su formación como chileno. Luego pasa a la escuela "superior" y después por el Liceo de Temuco, donde tuvo de "profesor de castellano al distinguido escritor i rector del establecimiento don Tomas Guevara", conocido por sus trabajos sobre el pueblo mapuche Psicolojia del Pueblo Araucano de 1908 y Folklore Araucano de 1911. Ambos libros cuentan con la cooperación de Manquilef y sobre Guevara dice haber llegado a tener "relaciones de íntima seriedad" (Manquilef 1911: 7). Luego entra a la escuela Normal de Chillán, llegando a ser profesor y luego director del Liceo de Temuco. Además, se desempeñó como profesor de "idioma mapuche en el internado araucano que sostiene la misión inglesa de Quepe" ${ }^{19}$. También trabajó en el Instituto Chileno alemán de Temuco y "el de señoritas denominado "Colegio de Santa Filomena". Manquilef pasa por todo el abanico de agencias educativas occidentales destinadas a civilizar al pueblo mapuche: primero como estudiante de escuelas y liceos, luego formándose como profesor en la escuela Normal, y finalmente como profesor en la misión anglicana, el colegio católico y

19 Según el antropólogo André Menard y el sociólogo Jorge Pavez -compiladores del libro Mapuche y Anglicanos. Vestigios fotográficos de la Misión Araucana de Kepe, 1896-1908- los anglicanos se diferenciaron de los católicos, en este caso particularmente de los capuchinos, en que aquellos aplicaban la lógica colonial británica donde se respetaban la cultura y las autoridades locales. Bajo el régimen de internado y la división sexual del trabajo a los niños y niñas de las misiones de Kepe y Chollcholl, también se les integraba el mapuzugun y se les fomentaba el nacionalismo cultural. 
otras instituciones, estales algunas y otras dependientes de las colonias europeas establecidas en el sur de Chile en la segunda mitad del siglo XIX. Estas agencias articulan la continuidad del avance colonial entre la evangelización de las almas y la incorporación de los cuerpos y el territorio al dominio del Estado $^{20}$. Recordemos que dentro de las concepciones etnográficas decimonónicas el monoteísmo era concebido como el estado religioso y cultural más "evolucionado" de las naciones. En este sentido, la educación estatal con un supuesto rol secular, nunca se separó de la labor evangelizadora cristiana. De hecho el Estado promovió la instauración de numerosas escuelas misionales tanto católicas como protestantes a manos de religiosos principalmente europeos (Menard y Pavez 2007, Quidel 2015, Porma 2015).

Junto al texto también aparece una foto de estudio de Manuel Manquilef, con corte de pelo y vestimentas occidentales, burguesas, cuello almidonado, corbatín, bestón y chaleco, sin ningún elemento que indique pertenencia al pueblo mapuche. En síntesis: un ciudadano chileno. José Quidel se refiere a lo que significó y significa el pasar por la escuela para el mapuche y cómo también se expresa en esta foto: "esos espacios llamados 'internados' donde encerraron a las personas, era el lugar ideal para transformar los cuerpos,

20 El contraejemplo de la biografía ejemplar de Manquilef fue otro colaborador de Tomas Guevara, Lorenzo Coliman, algunos de cuyos datos biográficos, junto a algunos comentarios sobre la educación de sujetos indígenas, aparecen en el libro Folklore Araucano del propio Guevara. Respecto a la vida de Coliman, Guevara escribe: "originario de Puren, paso su juventud en esas reducciones para ir a estudiar en seguida tres años a la Escuela normal de Santiago, cuyas aulas abandonó en 1879 para incorporarse de soldado al ejército que espedicionó contra el Perú. [...] Vuelto de la guerra fue intérprete del juzgado de Angol, empleo que dejó pronto para seguir la vida libre de la tribu de su tierra natal. Casóse allí con una joven de su raza, la cual se le fugo con una amante despues de algun tiempo. Coliman emigró a los alrededores de Temuco, donde ha contraido matrimonio i vive satisfecho de su suerte, compartiendo su tiempo entre las costumbres del pueblo a que pertenece i las tareas de enseñar a leer i escribir a niños indíjenas. [...] La vida de Coliman hace recordar de paso un fenómeno ampliamente comprobado por los investigadores de la raza araucana, i es que un jóven indíjena educado a medias, que permanece dos o tres años en el colejio, pierde toda señal de educación i esperimenta una regresion a los hábitos de barbarie cuando vuelve a su medio natural. [...] La influencia de la educación en los indíjenas es innegable; pero sus efectos se manifiestan de un modo mui lento, porque persisten por largo tiempo las tendencias hereditarias. [...] Las funciones psíquicas que primero se desarrollan en los agregados inferiores, son las de la sensibilidad, que predominan sobre las facultades de la intelijencia i de la voluntad. [...] No han comprendido, pues, los educadores de esta raza próxima a desaparecer o a modificarse, en ninguno de sus periodos históricos, la necesidad de producir, aunque a la larga, en las jeneraciones nuevas preferentemente, una mutacion o cambio que disminuya el estado instintivo i aumente las otras facultades mentales. Para esto habria sido indispensables leyes i planes de educacion adoptados para sociedades evolucionadas" (Guevara 1911: 4-5). 


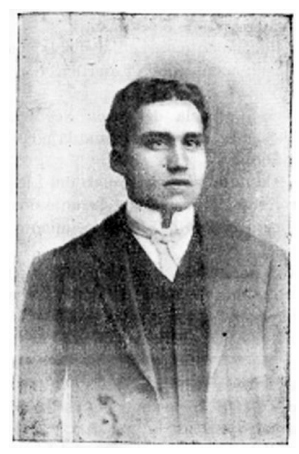

para estimular a dejar sus apariencias y formas de ser, para incorporar las nuevas formas, las otras" (Quidel 2015: 45). Y agrega respecto a los hombres, "teníamos que caminar como wigka, adquirir la personalidad wigka, la forma de peinarse, el corte de cabello, todo para parecerse a ellos. El aprender a mirar como wigka, sus formas de saludar, sentarse como ellos, 'aprender' a comer, vestirse como wigka" (Quidel 2015: 45).

Otro trasfondo sobre el que puede pensarse la petición de Lenz a Manquilef de escribir una autobiografía es el de la importancia que en ese tiempo tenía la novela de formación o Bildungsroman, sobre todo a partir del Romanticismo alemán, donde Goethe fue el representante más importante de este género con su Wilhelm Meister. Mijail Bajtin plantea en "La novela de educación y su importancia en la historia del realismo", que este género discursivo, que tiene sus orígenes en el mundo antiguo grecolatino, adquiere características propias durante el siglo XIX en Europa. Antes el mundo en general no cambiaba para el protagonista, en el siglo XIX "el hombre se transforma junto con el mundo, refleja en sí el desarrollo histórico del mundo. El hombre no se ubica dentro de una época, sino sobre el límite entre dos épocas, en el punto de transición entre ambas" (Bajtin 1979 / 1982: 211). El héroe de este tipo de novelas se transforma en un nuevo tipo de hombre. Este sujeto es la representación de una fuerza organizadora del futuro de todo un pueblo. Este es el límite que atraviesa la existencia de Manquilef y en el que se autorrepresenta como protagonista: el devenir biográfico dentro de la historia de un territorio en que conviven y se enfrentan la sociedad mapuche y la sociedad chilena.

Termina la biografía en marzo de 1909, momento en el cual es nombrado "profesor de Jimnasia y Caligrafía del Liceo de Temuco". Compartimos la lectura que Jorge Pavez hace sobre esta condición de ser profesor de caligrafía y gimnasia como "un gesto de doble afirmación. En el horizonte de esta fusión estaría un producir, a imagen de su propio cuerpo, una sola nación, a partir de una historia de cuerpos guerreros y una literatura escrita que alegoriza estos cuerpos" (Pavez 2015: 366).

\subsection{NotA AClARATORIA: "ORIGEN DE ESTE TRABAJO"}

Luego aparece el título del texto "comentarios del pueblo araucano (La Faz Social)", lo que marcaría la entrada al texto, como tal, de Manquilef. Inmediatamente abajo aparece otro paratexto bajo el subtítulo "origen de 
este trabajo" (comentarios I: 9 y 10), firmado por Lenz como director de la SFCh, y escrito en ocasión del éxito de Manquilef en el concurso antes mencionado. No aparece ni el lugar ni la fecha de su escritura pero se supone que al ser el acta del concurso de que se habla sería con anterioridad al 9 de octubre de 1910.

En este paratexto se relata la razón por la que se convocó al certamen en el que el texto de Manquilef resultó ganador: "se acordó adjudicarle el premio ofrecido i darle un voto de aplauso, pues su obra revela estudio i espiritu observador". El "certamen literario-científico" fue realizado para "conmemorar nuestra emancipacion política", refiriéndose a la celebración entonces de los 100 años de la República de Chile. En este certamen se dio la posibilidad de escribir "un trabajo que desarrolle una faz de la vida araucana", en donde se destaca el trabajo de Manquilef, "que tiene la particularidad de estar escrito en castellano y mapuche", donde "se desarrollan algunas costumbres de la raza i narran las particularidades de la vida íntima del araucano en sus relaciones sociales". Cabe mencionar que la utilización de ciertas calificaciones como "trabajo de cierto aliento", "está escrito en estilo sencillo" (Manquilef 1911: 10), que pueden llegar a denotar un gesto que subraya las limitaciones del texto, aunque en el caso de un texto etnográfico-folclórico esto puede entenderse también como una forma de elogio y reconocimiento.

El título original con que se presentó el texto a dicho concurso era "La faz social araucana", por lo que podemos pensar que el título con que se publicó finalmente fue una sugerencia de Lenz como editor de la revista y director de la SFCh, institución que convocó a un certamen de carácter etnográfico sobre "una faz de la vida araucana" (Manquilef 1911: 9). Respecto al título final con que apareció podemos decir que un "comentario" es una opinión, algo personal sobre un tema específico, que con ese nombre guarda una larga tradición en las distintas variantes del género ensayístico. También se puede establecer una conexión con un género literario autoetnográfico fundado por el célebre mestizo Inca Garcilaso y sus Comentarios reales de los Incas de 1609 , donde expone parte de la historia y cultura Inca.

Respecto al seudónimo Lef Kiman (su apellido con las sílabas invertidas) con que fue presentado, podemos interpretarlo como "aprenderé rápido", si traducimos lef como rápido y kiman, como forma futura de kimun, es decir, sabré o entenderé. Nuevamente aparece una lexía que denota el proceso de formación.

El último párrafo de esta explicación nos dice que esta es constancia de un acta firmada por Santiago Carberry, Carlos B. Frias y Leoncio Rivera. Un acta es un tipo de documento burocrático que da cuenta de un suceso en el devenir temporal de una institución, en este caso, se trata de la sociedad 
recién fundada con "el objeto de [...] fomentar el estudio del folklore chileno (F. Ch.) i facilitar la publicación de toda especie de trabajos referentes a esta ciencia" (Lenz 1909: 3). En el siguiente apartado analizaremos parte de su programa.

\subsection{Un ePitexto: Programa de la Sociedad de FolKLORE CHILENO, UNA DIDÁCTICA DE LA IDENTIDAD}

En este punto es necesario detenernos en lo que fue la SFCh, para entender los fundamentos ideológicos que están detrás de su fundación y así avanzar en la indagación de los pormenores de la publicación de estos Comentarios. En el Programa de la Sociedad de Folklore Chileno, presentado por Rodolfo Lenz, se nos dice que considera el folclore como una rama de la etnología:

una rama de la "ciencia del hombre" que busca la mayor parte de los materiales que se necesitan para la aplicación del método inductivo i comparado en la etnolojía. Recoje los mitos i todas las manifestaciones de las creencias populares, las leyendas, las consejas, los cuentos, cantos i proverbios, las supersticiones i costumbres. Mientras la etnolojía general debe siempre tomar en cuenta a todas las naciones del mundo, cualquiera que sea su grado de civilización y parentesco, el folklore se limita a una sola nacion o a un grupo de naciones que tienen historia comun, pero puede tambien limitarse hasta una sola provincia i aun a una sola clase de individuos. (Lenz 1909: 5)

Este texto de presentación es un resumen del discurso inaugural de la sociedad, del que Lenz advierte a pie de página que es una adaptación del libro del pangermanista "Dr. R. F. Kaindl, Die Volkskunde, ihre Bedeutung, ihre Ziele und ihre Methode [El folklore, su importancia, sus fines y su método]. Leipzig 1903" (Lenz 1909: 5).

Raimond Friedrich Kaindl fue un intelectual de Bukovina de origen alemán, que vivió gran parte de su vida en la ciudad de Czernowitz, actual Ucrania, entonces Imperio Austro-húngaro; estudió allí y trabajó en la Universidad de Bukovina, finalmente en Graz, siempre en el ámbito de la historia austríaca, la etnología, dedicando mucha atención a los alemanes de los Cárpatos. Kaindl fue uno de los primeros en reflexionar sobre el método del Volkskunde como ciencia. Según él lo mejor sería el método comparativo, $\mathrm{y}$ con ello promover la identidad nacional basada en una unidad cultural. Concebía el método comparativista también como un sistema educativo. Esta puede ser una de las razones por las que Lenz lo rescatara, porque su trabajo no se separa de un fin pedagógico, de lo que podríamos llamar una didáctica 
para la identidad. Esta concepción del folclore y lo popular implica lo que Angenot denomina una gnoseología, es decir, un "conjunto de reglas que determinan la función cognitiva de los discursos, que modelan los discursos como operaciones cognitivas" (2010: 40) ${ }^{21}$. Según Thomas Prendergast, el método comparado de Kaindl no solo era una metodología para el estudio del folclore, sino también un método de formación de ciudadanos. El docente o instructor partiría situándose en una costumbre familiar local, para luego situarla en una constelación de prácticas a nivel nacional y luego en lugares alejados a nivel supranacional, incluso en otros continentes, incluso de otras épocas ${ }^{22}$.

No deja de llamar la atención -y puede considerarse una osadía, otra forma en la que aparecía adelantado a su tiempo- el hecho de que Lenz rescatara a Kaindl, ya que el estudio del folclore en la academia del imperio Austro-húngaro, en ese tiempo, tuvo un papel bastante marginal, considerado como "historias de esposas viejas y canciones de mendigos" (Krauss, citado por Prendergast 2015: 1235, la traducción es nuestra), asuntos a los que se dedicaban diletantes y bohemios. Lo que podemos decir es que su modelo resultó útil tanto para políticas progresistas como para nacionalismos reaccionarios. En los estatutos de la SFCh, Lenz cita la parte final del último capítulo de Kaindl. Allí también nos dice la razón por la que hay que dedicarse al estudio del folclore, ya que ante el avance del progreso en "[1]a época del vapor i de la electricidad, del comercio mundial que todo lo nivela, aniquila también los materiales más preciosos que necesita la etnolojia" (Lenz 1909: 11). La etnología, la ciencia que estudia "lo que piensan los pueblos" (Lenz 1909: 5) debía ser considerada la base de la filosofía del futuro, ya que "si hasta ahora ningun sistema filosófico ha podido obtener validez universal, por buenas i profundas que hayan sido muchas de las ideas establecidas, esto se debe al hecho de que hasta hoi toda filosofia ha sido el resultado de la especulación de individuos aislados" (Lenz 1909: 6). Por eso los etnólogos y folcloristas deben tratar de:

21 Angenot aclara que: "Esta gnoseología corresponde a las maneras en que el "mundo" puede ser esquematizado sobre un soporte de lenguaje (maneras cuyo fondo es la "lógica natural"), esquematizaciones que constituyen la precondición de los juicios (de valor, de elección)" (ibid.).

22 De esta manera, "encontramos un esfuerzo concertado por parte de Kaindl para tender puentes entre provincias, naciones, imperios y civilizaciones en un campo conceptual cohesivo y unificador. El estudiante comienza con lo que sabe, y poco a poco se adaptan estas piezas del rompecabezas de conocimiento local en una imagen unificada del mundo y su historia" (Prendergast 2015: 1241. La traducción es nuestra). 
penetrar en el espíritu de los usos i costumbres, de la cultura, de las tradición i de la poesía de las naciones [..] en esa frase única del proverbio se refleja la mejor idea de una cabeza filosófica, que millares han tenido por correcta, i que por esto, se ha conservado a traves de los siglos i a pesar del cambio de opiniones, ¡ el oro, oro queda! Todo esto hay que recojerlo con la pluma i buril, i aun hai que formar museos. (Lenz 1909: 11)

Esta filosofía del porvenir también se asume como universal. El folklore deber ser la base de ese nuevo edificio. Se debe atesorar el saber popular, que aparece como la base económica de un nuevo pensamiento. De ahí la importancia del estudio del folclore "porque su tarea es acarrear la mayor cantidad de las piedras de las cuales se ha de componer el edificio de la filosofía del porvenir" (Lenz 1909: 12). Acá vemos un intento de asentar las bases teóricas, metodológicas y un programa del estudio del folclore y de los nacionalismos (de izquierda y de derecha), quizás de toda América del Sur, la creación de un patrimonio identitario frente al imperio de la economía mundial que todo lo iguala. El conocimiento colonial necesita, al igual que la economía, de materias primas, estas piedras que son el material etnográfico para crear una riqueza patrimonial. Pero este patrimonio cultural sería válido no como cultura viva sino solo en tanto espectáculo, es decir, solo exhibido en un museo ${ }^{23}$ (el nuevo edificio: la nueva filosofía), en una feria o incluso en un zoológico humano, como materia prima devenida a mercancía. Para concluir, podemos decir que Lenz recurre a Kaindl porque asume el método inductivo y comparado propio de la etnología para el estudio del folclore y este método se proyecta para la creación de identidades que la sociedad chilena solicitaba del nuevo modelo educativo, que también competía a Lenz como formador de docentes en el Instituto Pedagógico. Y volviendo al texto de Manquilef que nos preocupa en este trabajo, este es un sujeto que aprendió a trabajar la materia prima, la piedra, el artesano que es capaz de elaborar su propia experiencia, su cultura, su lengua, y ofrecerla a la cultura occidental ${ }^{24}$.

23 Giorgio Agamben escribe que la lógica de la sociedad de masas es la imposibilidad de usar que "tiene su lugar tópico en el Museo" (Agamben 2005: 109), lógica que puede llegar a incorporar todo lo existente dejando "simplemente la exposición de una imposibilidad de usar, de habitar, de hacer experiencia” (ibíd: 110). Según este autor el museo es el lugar donde la analogía entre religión y capitalismo se hace evidente.

24 Hoy en día, el Consejo Nacional de la Cultura y las Artes del Estado chileno llama a concursos similares al que Manquilef participó, como una proyección de memoria discursiva de SFCh: "Tesoros Humanos Vivos, propuesta de la Unesco a sus países miembros que en Chile implementa el CNCA, entrega cuatro distinciones: dos en las categorías de cultor individual y dos en cultor colectivo o comunidad local, consistentes en una certificación 
Por ahora dejaremos entre paréntesis el análisis de la "DEDICATORIA", "INTRODUCCION", firmada por Manquilef y los epígrafes para centrarnos en otros que son más relevantes para los fines de nuestro trabajo.

\subsection{CERCAMIENTO DE LA ESCRITURA: "ESPLICACIÓN DE LA ESCRITURA MAPUCHE” Y NOTAS AL FINAL DEL TEXTO}

Por cercamiento entendemos la acción de cercar, de establecer los límites de un territorio por medio del $\operatorname{cerco}^{25}$. La explicación de la escritura y las notas al final del texto lo entendemos como un cerco de la escritura de Manquilef, una marca de control que Lenz hace en el territorio textual de la escritura del mapuche. Una nota al pie de página deja en claro que, a fin de cuentas, son los estudiosos europeos, sacerdotes o científicos, las autoridades sobre la lengua mapuche ante el mundo winka:

(1) El señor Manquilef no usa el signo de ə para la vocal débil del mapuche, sino que la escribe a veces $u$ (tufeichi), a veces $\ddot{i}$ (eliz̨iln). En algunos casos escribe $i$ donde Febrés, Félix Augusta i yo escribimos $\ddot{u}(\mathrm{p}, \mathrm{g}$ ayin), otras veces vacila entre $\ddot{u}$ i $u$. Todo esto será debido a particularidades de su dialecto personal [R. L.]

COMENTARIOS

La no utilización de un signo que sí utilizan los europeos, según Lenz, es por la falta de dominio de todos los dialectos de su lengua del autor mapuche que sí dominarían los estudiosos. Nuevamente se subordina al sujeto mapuche al orden occidental: si aquel tiene el dominio de su lengua materna, este la posee en la diversidad de sus dialectos, la domina como objeto que extiende más allá del conocimiento del "hablante nativo".

pública de su calidad de Tesoro Humano Vivo y un estímulo económico de \$3.000.0000, para cultores individuales, y $\$ 7.000 .000$ para los colectivos. [...] El Consejo de la Cultura, a través del Departamento de Patrimonio Cultural, realiza un trabajo de continuidad con aquellos individuos y comunidades reconocidas, con el fin de cumplir el compromiso de contribuir a la salvaguardia del patrimonio cultural inmaterial por el cual fueron reconocidos. Ello, a través de iniciativas programáticas tendientes a la identificación, registro, investigación, reconocimiento, promoción y valoración de las expresiones de su patrimonio inmaterial." Fuente: http://www.cultura.gob.cl/patrimonio/tesoros-humanos-vivos/

25 Otra acepción de la palabra tiene que ver con el campo militar y tiene que ver con la sitiar un lugar determinado, que podríamos tomar en cuenta en tanto también fue una ocupación militar. Pero en este caso optamos por la significación relacionada con la acción de cerrar un lugar, que creemos más relevante con el momento histórico de la enunciación de los Comentarios. 
Esto se ve reafirmado al final del cuadernillo, donde aparece una extensa nota firmada por Lenz. En ella introduce un glosario para aclarar términos de "palabras chilenas" (Manquilef 1911: 60) y de "Palabras indias" (Manquilef 1911: 61). Acá se establece el dominio del significado de las palabras por parte del filólogo que presenta, comenta, es epigrafiado, sobre el espacio textual atribuido al autor mapuche, isomorfía del dominio colonial sobre el territorio mapuche:

*) Nota: Tanto en el testo castellano, como en la traducción interlinear, Manquilef ha usado un buen número de términos chilenos cuyo significado el lector estranjero no encontrará en los diccionarios castellanos. Doi a continuación una lista de estas palabras con su esplicacion. Por mas detalles véase mi diccionario etimolójico de las voces chilenas derivadas de lenguas indígenas americanas [Santiago 1905 a 1910; en comision K. W. Hiersemann, Leipzig]. (Manquilef 1911: 59)

Y finaliza la nota con una explicación fonética y semántica de los nombres de Manquilef:

El nombre Segundo del señor Manquilef en pronunciación mapuche suena Cheuntu. En este caso naturalmente la denominación india (= el que vuelve a ser jente) es lo primitivo i Segundo una castellanización falsa. Segundo, sin otra añadidura, es nombre frecuente en Chile.

Manquilef significa "el condor corrió" Lef-kiman su sendónimo [sic], quiere decir "pronto sabre". (Manquilef 1911: 60)

Explica primero de dónde viene el segundo nombre de Manquilef, "Segundo", una "castellanización falsa" - en palabras de Lenz-de "Cheuntu", que según Lenz quiere decir "el que vuelve a ser jente". Esto es una corrección al propio Manquilef que en su autobiografía explica que quiere decir "el que se vuelve jente" (1911: 6). La pequeña diferencia que hay entre ambas interpretaciones denota que Lenz explica el vocablo como un "volver a ser" persona, es decir como si hubiera dejado de ser para volver a ser; en cambio Manquilef lo traduce como un proceso de formación, el sujeto se vuelve a sí mismo. Por otro lado, nuevamente caracteriza el término mapuche ("denominación india") como primitivo y la adaptación fonética del mapuche al castellano como "falsa". Termina traduciendo el apellido y seudónimo del autor, que, como dijimos antes, hace referencia a un proceso de formación educativa, de adquisición de conocimiento en un futuro inevitablemente relacionado con el avance del progreso y la civilización.

Por su disposición textual, interpretamos esta nota como un cierre del cerco sobre la escritura de Manquilef. El lingüista, etnólogo y folclorista completa de esta manera el control sobre lo que se supone es el primer documento escrito legítimamente araucano. 


\section{CONCLUSIONES Y PROYECCIONES DE ESTE TRABAJO}

Para cerrar este trabajo quizás es bueno volver a la pregunta planteada por Gayatri Spivak (1998): “Puede hablar el subalterno?”. En trabajos posteriores esperamos analizar de qué manera estos ideologemas se proyectan en otras obras de Manquilef y de Lenz.

El recorrido por algunos de los paratextos de los comentarios de Manquilef nos permitió ver de qué manera se presentan y articulan ideologemas, expresados de manera explícita o implícita, que implican una representación social - una forma de conocer y significar- la lengua y la cultura mapuche. En estos, la escritura del mapuche aparece subordinada a la del sabio alemán, recurriendo a una serie de recursos discursivos. En este sentido Lenz es también el autor, en tanto autoridad especialista del tema del que trata el texto de Manquilef.

Si consideramos la disposición grafica de los paratextos dentro del dispositivo de la revista, entendemos que es un cercamiento sobre la escritura del autor mapuche. En los paratextos analizados vemos cómo van surgiendo distintos ideologemas que están destinados a incluir lo mapuche dentro del folclore chileno. El primero de ellos se nos muestra en el prefacio escrito por Lenz al nombrar el poema épico La Araucana, como texto fundacional patrio, y que tiene que ver con el origen racial de lo chileno, que sería producto del mestizaje entre españoles y mapuche, dado en un contexto de enfrentamiento bélico. Otro ideologema importante es el que surge de una metáfora de la arena circense, y que supone el espacio público de la cultura impresa representado como un espectáculo. El concepto de cultura de la época, tanto letrada como popular, pasa por la necesidad de ser exhibida ya sea en un texto etnográfico o en un circo, o en un zoológico humano, en los casos más deshumanizados. La cultura como proceso vivido, bajo su valor de uso no interesa a los ojos occidentales.

El autor mapuche al representarse en su autobiografía-escrita por petición de Lenz- en su infancia, momento en que vivió como mapuche, lo hace siendo adulto, momento en que vive como winka (occidental / chileno). En este sentido se puede plantear que existe una transacción para poder publicar: el costo de ser miembro de SFCh es ofrecer la exhibición autobiográfica de su infancia. Al revisar su autobiografía pudimos percatarnos de cómo este devenir en la historia personal del sujeto puede ser entendido como una metáfora que pretendía demostrar el propio devenir de la nación chilena, que en su propio desarrollo histórico se representa en un pasado primitivo (su infancia) como mapuche y en su presente moderno (adultez) como chileno. Esta alegoría también es una expresión del cambio de mundo que implicó la 
incorporación por parte del ejército chileno del territorio mapuche, lo que supuso un cambio drástico del mundo para el pueblo mapuche.

Por último, debemos entender el programa de Sociedad de Folklore Chileno como un epitexto que contribuye a reponer sentidos en el aparato paratextual objeto de nuestro análisis. Lo consideramos como tal, ya que otorga también una dirección a la recepción del texto de Manquilef, nacido a partir del primer concurso llamado por la SFCh. En dicho programa la adopción del modelo de Kaindl expresaría no solo la distinción del objeto de estudio, la cultura de cada pueblo, y del método de la ciencia etnográfica y específicamente del folclore, sino también una didáctica de la identidad nacional.

La noción de cultura, entendida desde los ojos imperiales, necesariamente pasa por la posibilidad de ser esta exhibida y explicada bajo los parámetros occidentales. El discurso del sujeto subalterno, que se autorepresenta y representa la cultura de su pueblo, lo hace teniendo como supuestos los de la cultura moderna de origen europeo, a la cual le interesa exponer y comprender las experiencias vividas de cada pueblo, para ser controladas bajo la lupa del saber científico. En este sentido, este sujeto es una creación de occidente.

\section{REFERENCIAS BIBLIOGRÁFICAS}

Agamben, Giongio. 2005. Elogio de la profanación. Profanaciones, pp. 82-119. Buenos Aires: Adriana Hidalgo.

Altschul, Nadia. 2012. Geographies of Philological Knowledge. Postcoloniality and the Transatlantic National Epic. Chicago/London: University of Chicago Press.

Angenot, Marc. 2010. El discurso social, los limites históricos de lo pensable y lo decible. Buenos Aires: Siglo XXI.

1982. Presupuestos, Topos, Ideologema. Traducción de Lía Varela, extraído de $L a$ Parole Pamphlétaire. París: Payot.

Arnoux, Elvira Narvaja DE. 2008. Los discursos sobre la nación y el lenguaje en la formación del Estado (Chile, 1843-1862). Buenos Aires: Santiago Arcos.

Arnoux, Elvira Narvaja de y José Del Valle. 2010. Las representaciones ideológicas el lenguaje. Discurso glotopolítico y panhispanismo. Spanish in Context 7: 1-24.

Augusta, (Fray) Felix José de. 1903. Gramática Araucana. Valdivia: Imprenta central J. Lambert.

BAJTín, MijaIL. 1982. La novela de educación y su importancia en la historia del realismo. Estética de la creación verbal, pp. 197 - 243. Buenos Aires: Siglo XXI.

Barros Arana, Diego. 1884/1999. Historia General de Chile, Tomo I. Santiago: Editorial Universitaria.

Barros Arana, Diego y Rodolfo Lenz. 1893. La lingüística americana; su historia y su estado actual. Anales de la Universidad de Chile 84: 985-1029. 
Barthes, Roland. 1970. Mitologías. México: Siglo XXI.

Bauman, Richard y Charles Briggs. 2003. Voices of Modernity. Language Ideologies and the Politics of Inequality. Cambridge: Cambridge University Press.

BengoA, José. 1985. Historia del pueblo Mapuche. Santiago: Ediciones Sur.

Bentivegna, Diego. 2013. Un arcángel devastador: Gramsci, las lenguas, la hegemonía. Antonio Gramsci, Escritos sobre el Lenguaje. Caseros: EDUNTReF.

Bourdieu, Pierre. 1987. Cosas Dichas. Barcelona: Gedisa.

Chartier, Roger. 1999. Trabajar con Foucault: esbozo de una genealogía de la "función de autor". Signos Históricos I (1): 11- 27.

Crow, Joanna. 2015. Mapudungun and the Contested Process of (Nation) State Building in Nineteenth-Century Chile. En Anna Havinga y Nils Langer (eds.). Invisible Languages in the Nineteenth Century, pp. 51-70. Bern: Peter Lang.

Del VAlle, José. 2005. La lengua, patria común: política lingüística, política exterior y el posnacionalismo hispano. En Roger Wright y Meter Ricketts (eds.). Studies on iberoromance linguistics dedicated to Ralph Penny. Newark: Juan de La Cuesta.

Di Stefano, Mariana. 2013. El lector libertario, prácticas e ideologías lectoras del anarquismo argentino (1898 - 1915). Buenos Aires: Eudeba.

ENNIS, JUAN. 2012. Rudolf Lenz en la encrucijada criolla. Signo \& Seña, 22: 181-214.

2013. Reseña: Nadia R. Altschul. 2012. Geographies of Philological Knowledge. Postcoloniality and the Transatlantic National Epic. Chicago y Londres: Chicago University Press. Revista Argentina de Historiografia Lingüistica V (1): 77-84. http:// www.rahl.com.ar/Revistas/I\%20-\%202013/ennis-RAHL-(1)2013.pdf

2015. Reescribir el origen para escribir el retorno: filología, exilio y nación en el Cid de Andrés Bello. En Andreas Gelz y Marco-Thomas Boshard (eds.). Return Migration in Romance Cultures, pp. 103-126. Freiburg: Rombach.

2016. Rodolfo Lenz: economías de la lengua y políticas de la lingüística. Boletín de Filología 51(1): 117-145.

ERrington, JosePh. 2008. Linguistics in a Colonial World. A History of Language, Meaning and Power. Oxford/Malden, MA: Blackwell.

Gennette, Gerard. 2001. Umbrales. Buenos Aires: Siglo XXI.

Guevara, Tomás. 1911. Folklore Araucano. Santiago: Imprenta Cervantes.

Lenz, Rodolfo. 1897. Estudios Araucanos. Santiago: Imprenta Cervantes.

1894. Ensayos filolójicos americanos I. Introducción al estudio del lenguaje vulgar de Chile en Anales de la Universidad de Chile. Anales de la Universidad de Chile 87: 113-132. 1909. Programa de la Sociedad del Folklore Chileno. Santiago: Imprenta y encuadernación Lourdes.

1940. Para el conocimiento del español de América. En Amado Alonso (ed.). El Español en Chile, pp. 210-267. Buenos Aires: Instituto de Filología de la Facultad de Filosofía y Letras de la Universidad de Buenos Aires.

Manquilef, Manuel. 1911. Comentarios del Pueblo Araucano (la Faz Social). Santiago: Imprenta Cervantes.

MenARd, ANDrÉ. 2006. Emergencia de la tercera columna en el texto: "La faz social", fragmento de los Comentarios del pueblo araucano de Manuel Manquilef. Anales de Desclasificación 1: La derrota del área cultural 2: 927-37.

2014. ¿Puede cantar el subalterno? Comentario al libro de Margarita Canio Llanquinao y Gabriel Pozo Menares. Historia y conocimiento oral mapuche. Sobrevivientes de la "Campaña del Desierto" y "Ocupación de la Araucanía" (1899-1926). Revista Musical Chilena 68(222): 89-97. 
Menard, André y Jorge Pavez. 2007. Mapuche y anglicanos: Vestigios fotográficos de la Misión Araucana de Kepe, 1896-1908. Santiago: Ocho Libros Editores.

Mallon, Florencia. 2011. La doble columna y la doble consciencia en la obra de Manuel Manquilef. Revista de Antropología 21: 59-80.

PAS, Hernán. 2012. ¿Ecos de Lautaro?: las lenguas indígenas como patrimonio cultural del nacionalismo criollo en el siglo XIX. Anclajes 16(2): 73-92.

PaVez, Jorge. 2003. Mapuche ñi nütram chilkatun/Escribir la historia Mapuche: Estudio posliminar de Trokinche müfu ñi piel. Historias de familias. Siglo XIX. Revista de Historia Indígena 7: 7-53.

2015. Laboratorios etnográficos, los archivos de la antropología en Chile (1880 -1980). Santiago: Ediciones de la Universidad Alberto Hurtado.

PAYAS, GERTRUDIS. 2015. Tan verídica como patriota: La pugna sobre traducción entre Rodolfo Lenz y Manuel Manquilef. CUHSO 25 (2): 83-114.

Pinto, Jorge. 2000. La formación del Estado y la Nación, y el pueblo mapuche. De la inclusión a la Exclusión. Santiago: Dibam.

Porma, Juan. 2015. Violencia Colonial en la Escuela: el caso de la comunidad José Porma en el siglo XX. Comunidad de Historia Mapuche, Awükan ka kuxankan zugu Wajmapu mew, Violencias coloniales en Wajmapu, pp. 189-205. Wajmapu: Ediciones Comunidad de Historia Mapuche.

Pratt, Mary-Louise. 2010. Ojos imperiales. Literatura de viajes y transculturación. Buenos Aires: Fondo de Cultura Económica.

Prendergast, Thomas. 2015. The Social Democrats of Scholarship: Austrian Imperial Peripheries and the Making of a Progressive Science of Nationality, 1885-1903. Religions 2015 (6): 1232-1248. www.mdpi.com/journal/religions

QuideL, José. 2015. Del por qué y cómo fueron violentados y sobrepasados los mapuche en su pensamiento y espiritualidad. Comunidad de Historia Mapuche. Awükan ka kuxankan zugu Wajmapu mew, Violencias coloniales en Wajmapu, pp. 37-55. Wajmapu: Ediciones Comunidad de Historia Mapuche.

Soto, Guillermo. 2016. Rodolfo Lenz y la enseñanza del castellano como idioma patrio en Chile. Boletín de Filología 51(1): 211-238.

SpIvaK, G. C. 1998. ¿Puede hablar el sujeto subalterno? Orbis Tertius 3(6): 175-235. http:// www.fuentesmemoria.fahce.unlp.edu.ar/art_revistas/pr.2732/pr.2732.pdf

Velleman, BARRY. 2007. La ideas lingüísticas y pedagógicas de Eduardo de la Barra y su polémica con Lenz y Hanssen. Contextos. Estudios de Humanidades y Ciencias Sociales 18: 179-193.

WiLliams, Raymond. 1988. Marxismo y literatura. Barcelona: Península. 